\title{
OPPORTUNITIES FOR INDIAN HEALTH CARE INDUSTRY
}

\section{Sanjeev Kumar K. M.*}

\section{Introduction}

The Indian Healthcare industry is expanding phenomenally. Availability of latest technology in diagnostics \& treatment devices, World-class infrastructure and nursing care - factors that have further empowered medical practitioners and enabled them to deliver healthcare that consistently meet international standards. India's IT capability has made significant contributions in healthcare administration, and helped improve efficiencies and control cost of care delivery. The 'high qualitylow cost' care delivery is dominated by the private healthcare providers who account for $65 \%$ of the domestic healthcare needs. The growing Indian middle class (450 million) with higher disposable incomes is driving this demand for quality healthcare. This segment of people is well informed on the latest developments in healthcare delivery and is willing to pay for their healthcare needs. The Indian healthcare providers have also emerged as significant players in the international market making India a preferred 'Health \& Medical Tourism Destination'

With new terms such as health tourism, healthcare outsourcing and medical back office support being bandied about, given the right mix of government push and private sector initiative India could emerge as a cost-effective healthcare service provider in South Asia and Southeast Asia and indeed to the rest of the world. Some of the latest trends are quite interesting. The British government is contemplating to fly its citizens down to India for treatment to clear up long waits for treatment and surgeries in British hospitals. Hospitals in Kolkata have long queues of patients from Bangladesh waiting for appointments with Indian medical specialists. And, now, the bus service between India and Lahore has opened up new opportunities for the people of Pakistan to avail of better quality healthcare in India.

The statistics are impressive. According to India's ministry of external affairs, the Indian healthcare industry, which comprises hospital services, healthcare equipment, managed care and pharmaceuticals, is poised to grow 13 per cent annually for the next six years. India could emerge as a major player owing to its high population. According to the Insurance Regulatory and Development Authority, the Indian healthcare industry has the potential to show the same exponential growth that the software and pharmaceutical industries have shown in the past decade. Only 10 per cent of the market potential has been tapped till date.

*Faculty, National Institute of Fashion Technology, Bangalore 
The growth of the healthcare industry is to be fuelled by the rising purchasing power of the Indian middleclass, which is willing to shell out more for quality healthcare that is today more available than, say 50 years ago, thanks to the involvement of the private sector in the healthcare industry and hospital management. With the kind of interest in availing of Indian healthcare services shown by other countries, the growth could be more than what has been calculated, feel industry watchers. Privatization of healthcare in India is the key to the resurgence of this sector. A Central Bureau of Health Intelligence study indicates that a majority of Indians of the middle- and high-income groups have confidence in healthcare products and services offered by private hospitals than the government-owned healthcare agencies. On an average, private healthcare service is 60 per cent more expensive than the government-owned ones.

\section{Market Overview}

Healthcare has emerged as one of the largest service sectors in India. In 2004, national healthcare spending equaled about 5.2 per cent of nominal GDP, or about US\$ 34.9 billion (IBEF2005). Healthcare spending in India is expected to rise by 12 per cent per annum through 2005-09 (in rupee terms) and scale up to about 5.5 per cent of GDP, or US $\$ 60.9$ billion, by 2009 . Other estimates suggest that by 2012 , healthcare spending could contribute 8 per cent of GDP and employ around 9 million (million) people. From a pan-India perspective, presently there are more than half a million doctors employed in 15,097 hospitals. Additionally there are 0.75 million nurses, who look after more than 870,000 hospital beds. During the previous decade, the number of doctors has increased by 36.6 per cent. An estimated 30 per cent of medical practitioners hold specialist Qualifications

\section{Table 1}

National Health care indicators

\begin{tabular}{|l|c|c|c|c|c|c|}
\hline \multicolumn{1}{|c|}{ Particulars } & 2004 & 2005 & 2006 & 2007 & 2008 & 2009 \\
\hline Life expectancy average years & 64 & 64.3 & 64.7 & 65.1 & 65.4 & 65.8 \\
\hline Health care spending RS billion & 1582 & 1763 & 1967 & 2216 & 2463 & 2771 \\
\hline Health care spending US \$ & 34.9 & 40.4 & 45.7 & 52.1 & 56 & 60.9 \\
\hline Health spending as \% of GDP & 5.2 & 5.3 & 5.3 & 5.4 & 5.4 & 5.5 \\
\hline & 32 & 37 & 41 & 46 & 49 & 53 \\
\hline
\end{tabular}

Source: US Census Bureau; Economist Intelligence Unit.

According to a week -TNS survey conducted in January 2005 All India institute of Medical sciences, Delhi topped the list followed by Apollo hospitals Chennai

Table 2 gives the list of top 11 hospitals in India. 
Table 2

List of Top 11 Hospitals in India

\begin{tabular}{|c|l|}
\hline Rank & \multicolumn{1}{c|}{ Hospital } \\
\hline 1 & All India Institute of Medical Science, Delhi \\
\hline 2 & Apollo Hospitals, Chennai \\
\hline 3 & Post Graduate Institute of Medical Education \& research, Chandigarh \\
\hline 4 & Chrsitain Medical College, Vellore \\
\hline 5 & Sankara Nethralaya, Chennai \\
\hline 6 & Bombay, Hospital, Mumbai \\
\hline 7 & National Institute of Mental Health and Neurosciences, Bangalore \\
\hline 8 & Jaslok Hospital, Mumbai \\
\hline 9 & Sanjay Gandhi Post Graduate Institute of Medical Sciences, Lucknow \\
\hline 10 & Jawaharlal Institute of PG Medical Education \& Research, Pondichery \\
\hline 11 & Tata Memorial Hospital, Mumbai \\
\hline
\end{tabular}

Source: The week TNS survey, 2005

\section{Health care market drivers}

\subsection{Growing incomes and literacy bode}

Much of India's healthcare expenditure comes from private patients' pockets, primarily the higherincome households. Tertiary-care treatments tend to be expensive. The top 33 per cent income earners in india accounted for 75 per cent of total private expenditure on healthcare in 2004 (IBEF2005). Rich households (the top 8 per cent) paid US $\$ 578$ per treatment and hospitalization in 2004, three times the overall average of US\$ 191. The proportion of households in the low income group has declined significantly. Rising incomes are expanding the rich and middle-income groups, and they are expected to form 49 per cent of total households in financial year 2010, as compared with 33 per cent in financial year 2004, thus driving growth.

A survey by NCAER, an independent economics research agency, suggests that per-capita expenditures on healthcare rise with higher education levels. Households that have higher education levels tend to spend more per illness than households with lower education levels. Rising literacy in India is improving health awareness, especially about lifestyle-related diseases which tend to be more costly to treat than infections. 


\subsection{Shift to lifestyle-related diseases to drive higher healthcare spends}

While rising incomes and growing literacy are likely to drive higher per capita expenditures on healthcare, the shift in disease profiles from infectious to lifestyle-related diseases are expected to raise expenditures per treatment. Lifestyle-related diseases are typically more expensive to treat than infectious ones. In 2001, the average inpatient cost for lifestyle-related diseases (cardiac problems, digestive issues etc.) was US\$ 658 compared to US\$ 91 for infectious diseases. India's disease profile is expected to follow the same pattern as in developed economies. Based on demographic trends and disease profiles, lifestyle diseases - cardiovascular, asthma and cancer have become the most important segments, and in-patient spending is expected to represent nearly 50 per cent of total healthcare expenditure. In the inpatient market, the share of infectious diseases is expected to decline from 19 per cent in.2004 to 16 percent in 2008. The number of cardiac-disease-related treatments in India is expected to grow from 1.5 million to 1.9 million per year over 2004-08, which would constitute 5.1 per cent of all treatments, The spend share of inpatient cardiac treatment is estimated to grow to 19 per cent of the total in 2008 from 16 percent in 2004. This would drive a 13.4 per cent CAGR in the inpatient cardiac care market from US $\$ 1.2$ billion in 2004 to US $\$ 2.04$ billion in 2008 . The average realization per inpatient for cardiac related treatment is much higher than for other disease segments.

\subsection{Increased life expectancy and an ageing population.}

In the domestic market, health spending will be sustained by two demographic trends: increased life expectancy and an ageing population. Life expectancy, which averaged 63.3 years in 2000-04, is expected to increase to 65.1 years in 2005-09 and to 66 years in 2006-10. The proportion of the population aged 65 years and over is also on the rise, and will increase from 4.7 per cent in 2000 to 5.3 per cent in 2005 and 5.8 per cent in 2010 . Although the rate of ageing in India is slower than the developed world, the large population makes any increase significant in terms of absolute numbers, and therefore also in terms of market potential.

\subsection{Rising share of the private healthcare sector}

The private provides the majority of healthcare services in India sector. In 2002 fee-charging private companies accounted for around 82 per cent of overall healthcare expenditure, with various levels of government covering the remaining 18 per cent. The contribution of the private healthcare sector is on the rise, with investments from the corporate sector steadily growing since the mid-1990s. In the last few years, a number of new players have entered the healthcare delivery sector, and set up specialty and super-specialty centers. In the government sector, the states provide the bulk of healthcare. Presently, the public spending is at a level of 1.3 per cent of the GDP. Public spending on healthcare will continue to rise, but the prospect of large and sustained increases is low. It is expected to increase to 3 per cent over the next few years. 


\subsection{Significant investment opportunities for private sector}

Limited government investment provides significant opportunities for private healthcare service providers, as large investments are required to scale up the country's healthcare infrastructure. India's healthcare infrastructure needs substantial investment. By certain estimates, to reach even half of China's current beds per 1,000 population over the next 10 years, India would need an additional 920,000 beds entailing an investment of between US $\$ 32$ billion and US\$ 49.1 billion, assuming that 20 per cent of those beds would be in the tertiary-care segment. The government is likely to meet only 15-20 per cent investment in hospital beds, assuming it increases expenditures by 6-7 per cent from the current base. Assuming 10-15 per cent commitment from international donors, there would be a shortfall of 70 per cent, which could be funded by private companies. Similarly, to match China's level of physician availability (1.1 per 1,000 population) over the next 10 years, it is estimated that an additional 818,000 physicians would be needed which translates into a need for more medical schools. Investment is also needed in medical equipment and training facilities for professionals such as nurses and pharmacists. India's unmet demand for healthcare facilities, rapidly changing demographics, increasing private spending on healthcare, and a readily available intellectual pool are fuelling the growth of the healthcare industry and making it highly attractive for international investors

\subsection{Overburdened health infrastructure \& high costs in the West}

The healthcare systems in Europe and the United States are under severe pressure; particularly the National Health Service in the UK, which has a long list of patients waiting for over a year for surgery. In the US the healthcare crisis has a different dimension. Around $\mathbf{5 0}$ million citizens are uninsured, with even the insured having to pay dearly for treatment. Further, the shortage of paramedical professionals such as nurses has aggravated the situation. Patients from the US are now regularly beating a path to India, as many of their insurance companies have entered into tie-ups with private Indian hospital chains.

\subsection{India's low cost of medical care}

India offers highly cost-competitive medical treatment and technological advances in areas such as cardiology, cosmetic and orthopedic surgery, dentistry, eye care and preventive health checks. India offers world-class cardiac bypass surgery, hip replacements, organ transplants, cosmetic, dental surgery and vision correction. Costs of comparable treatment in India are on average one eighth to one fifth of those in the West. For instance, a cardiac procedure costs anywhere between US $\$ 40,000-60,000$ in the United States, US $\$ 30,000$ in Singapore, US $\$ 12,000$ 15,000 in Thailand and only US $\$ 3,000-6,000$ in India. Likewise, the associated costs of surgery are also low. Not only are skilled Indian surgeons available for less, they are also less susceptible to costly litigation. The cost of malpractice insurance in New York is around US $\$ 100,000$ but only US $\$ 4000$ in India. This brings down the overall cost of treatment. 
With diagnostic tests in India being inexpensive, India also has the potential to emerge as a hub for preventive health screening. At a private clinic in London a health check-up for men that includes blood tests, electrocardiogram tests, chest X-Rays, lung tests and abdominal ultrasound costs around £350. In comparison, a comparable check-up at a clinic operated by Delhi-based healthcare company Max Healthcare costs US\$ 84. A Magnetic Resonance Imaging (MRI) scan costs US $\$ 60$ at Escorts Hospital in Delhi, compared with roughly US $\$ 700$ in New York. The overall cost of travel and treatment in India is still far less than the expense of just the medical treatment in many western countries (IBEF 2005).

A study by the India Brand Equity Foundation (IBEF) in 2004 shows how competitive India is in comparison with Thailand, another leading medical tourism destination. Thailand has a cost advantage over India in only two categories: plastic surgery and breast augmentation. India is cheaper than Thailand across a whole range of otherand more serious surgery categories as the chart below indicates.

Table-3

Cost advantages of India in comparison with Thailand

\begin{tabular}{|c|c|c|}
\hline Surgery & Thailand & India \\
\hline Bone marrow transplant & US\$ 62500 & US\$30000 \\
\hline Liver transplant & US\$75000 & US $\$ 40000$ \\
\hline Open Heart surgery & US\$ 14250 & US $\$ 4400$ \\
\hline Hip transplant & US\$ 6900 & US $\$ 4500$ \\
\hline Knee surgery & US $\$ 7000$ & US\$ 4500 \\
\hline Hysterectomy & US\$ 2012 & US\$ 511 \\
\hline Gall bladder removal & US\$ 1755 & US\$ 555 \\
\hline
\end{tabular}

Cost in US \$

Source: IBEF research

\section{Market opportunities}

Government of India has accorded a high priority to the healthcare sector by an increased budgetary outlay and heavily slashed customs duty on imports of medical equipments. Also there are special incentives being provided for setting up new Hospitals. These initiatives are giving fillip to various market opportunities in the segments detailed below. 


\subsection{Medical tourism}

Medical tourism has gained momentum in India over the past few years, a trend underpinned by India's low-cost advantage and the emergence of new high-quality healthcare service providers. In India, approximately 1,80,000 patients arrived in 2004 from across the globe for medical treatment. The medical tourism market in India, estimated at US\$333 million in 2004 grew by about 25 per cent and is predicted to become a US\$ 2 billion-a-year business opportunity by 2012 .

India is seeing a surge of patients from developed countries as well as from countries in Africa and South and West Asia that lack adequate healthcare infrastructure. The emergence of low-cost, high value specialist medical care territories in India has been noteworthy. For instance, New Delhi has emerged as a prime destination for cardiac care, as has Gujarat. Similarly, Chennai has established a niche for quality eye care, while Kerala and Karnataka have emerged as hubs for state-of-the-art ayurvedic healing. These "medical hotspots" are beginning to witness an influx of health tourists from non-traditional geographies. Among others, foreign health travelers to India comprise a large number of Non Resident Indians.

Due to the surge in medical tourism, some of the major corporate hospital groups in India such as Apollo, Fortis, Max, Wockhardt and Manipal have made significant investments in setting up state-of-the-art hospitals in major Indian cities. Fresh healthcare capacities that are coming up will help sustain the trend

\subsection{Hospital Services}

India is undergoing a major transition in its healthcare delivery system. The change started with the liberalization policies ushered in the early 1990s, which began to attract private investments into the healthcare sector. Private sector dominates healthcare delivery in India At present, India's healthcare burden has gone beyond the Government's budgetary applications and reduced public spending is leading to poor availability of services in the government hospitals. Private players (which include hospitals, nursing homes and charitable trusts) account for almost 78 percent of the healthcare delivery market. Over the last few years an estimated 95 per cent of new hospital beds have come up in the private sector. The market for hospital services in India is estimated at over US\$ 4 billion. The increased spending power of the 250-300 million strong middle classes is driving growth opportunities for corporate healthcare providers. Factors like privatization of medical insurance, apart from giving rise to a new healthcare delivery system, are making the market more attractive for international and national corporate players. These trends have led large corporate players such as the Apollo Group. Wockhardt, Fortis and Max Healthcare to rapidly expand their operations in India. In order to gain competitive advantage, these Indian corporate players are increasingly entering into collaborations with established global leaders. 


\subsection{Medical devices}

The medical devices market in India is highly promising. The market size for medical devices in India is expected to touch US $\$ 1.7$ billion by 2010 , against US $\$ 1.2$ billion presently. The demand for hi-tech products constitutes close to 80 per cent of the overall market in India. Since domestic production comprises primarily of low-tech devices; there is a higher involvement of foreign companies in sourcing hi-tech devices, which alone account for US $\$ 770$ million of market value. Presently, nearly 90 per cent of the demand is being met by imports from countries like USA, Japan and Germany.

\subsection{Pathology Services}

The US $\$ 500$ million domestic pathology industry has been growing over the last five years at an estimated Compound Annual Growth Rate (CAGR) of 20 per cent per annum. It currently comprises almost 2.5 per cent of the overall healthcare delivery market. With 40,000 independent pathology laboratories in the country, the industry is highly competitive and price driven.

\subsection{Molecular diagnostics and pharmacogenomic testing}

Molecular diagnostics is the fastest growing segment of the in-vitro diagnostics (IVD) market with a projected growth of 25 per cent per annum. Viral diagnostics, immune system disease diagnostics, bacterial, parasitic and fungal identification, cancer diagnosis and monitoring are the segments where molecular technologies enjoy significant cost-benefit advantage. Similarly, pharmacogenomic testing too is believed to usher in an era of personalized medicine where diagnostic tests that will help in selecting the best of the several therapies will be a prerequisite for prescribing a therapy. With the Government expected to bring in a relaxation on customs duty and service tax, molecular diagnostics and pharmacogenomic testing too are touted as the future drivers of the diagnostic industry. By 2010 , two million patients are expected for clinical trials in India; translating into 20 million tests.

\subsection{Preventive healthcare and health insurance}

Increasing health consciousness among common people has created avenues for preventive healthcare. Hospitals have started witnessing a number of patients who visit for health check-ups as a preventive measure. The various health check-up packages offered include a combination of blood sugar, cholesterol, urine, stool, digital chest X-Ray, ECG, general examination, blood group, blood sugar, liver profile, proteins, lipid profile, cholesterol, and renal profile. Around 70 per cent of treatment decisions in the country are based on lab results. This trend has further led to newer avenues for companies involved in carrying out diagnostic tests. The entry of foreign health insurance companies in India is proving to be an important driver of the domestic diagnostic industry as coverage of pathology services is inevitable in the policy. 


\subsection{Telemedicine}

In India, only about 27 per cent of the population lives in urban areas, while a sizeable 73 percent of the population is rural. While 72 per cent specialist doctors practice in urban areas, only 25 percent reside in semi urban areas and a mere 3 per cent in rural areas. The outcome of this lop-sided distribution is that 80 per cent of the medical facilities are concentrated in urban areas and a mere 20 per cent in rural areas, which continue to remain deprived of proper healthcare facilities. The answer to patient treatment in inaccessible areas in India with fewer medical facilities is telemedicine. The exponential growth in the ICT (Information \& Communication Technologies) sector and the plummeting telecom costs are making India highly competitive in telemedicine. The early successes of pioneers such as Apollo Hospitals, Narayana Hrudalaya, have resulted in increased acceptance and proliferation of telemedicine. At present, there are around 120 telemedicine centers spread in the country.

\subsection{Healthcare BPO}

Spiraling healthcare costs, unbearable squeeze on margins, process inefficiencies, acute talent shortage and an aging population are compelling healthcare establishments in the US and Europe to look at Indian healthcare BPOs. Outsourcing healthcare business processes to Indian service providers can result in cost savings to the tune of 20-30 per cent. The global market for outsourced services from the healthcare industry was estimated to be worth US\$3.6 billion in 2004 and is projected at US\$24 billion in 2008 . The estimated opportunity for India is US\$ 4.5 billion by 2008 , employing about 200,000 people.

\subsection{Health Insurance}

India offers tremendous opportunity for private medical insurance players. Increasing awareness levels and large-scale group insurance policies have pushed growth in the health insurance segment in recent years.

\section{Conclusions}

Indian healthcare scenario is discussed in this case. The structure of healthcare industry, which forms the crux of policy construction and functioning of the healthcare delivery system in India, has been narrated. Major findings of this case are

Health Care Industry in India is poised to tremendous growth. Major reasons for the growth; being the booming economy and higher literacy, which have aided people, seek for better living conditions. Higher life expectancy has raised the average life span but has made this section of population prone to old age diseases. Life style diseases are on the rise. 
Opportunity for growth in the healthcare sector is high. Policy guidelines of government has put healthcare as primary right of a citizen, thereby making it the most important service for the sustenance of life. The Indian healthcare also has the competitive advantage of cost over the West. Qualified and trained doctors providing value-added services at a lower cost has attracted medical tourism. Telemedicine has aided distance consultancy and medication. These multiple opportunities have enabled Indian healthcare to offer the world their expertise and services. 


\section{REFERENCES}

1. The week TNS survey, The Week, April 24, 2005 issue. Healthcare industry will boost the Indian economy bio spectrum march 15, 2006.

2. Droste, Therese, "Deep marketing cuts unfair, unwise, "Hospitals, June 5, 1989, p. 52.

3. Duggal R. 2000. The private health sector in India: nature, trends, and a critique. New Delhi: voluntary health association of India.

4. Frost and Sullivan, Health Care Industry will boost the Indian Economy, Bio-Spectrum, March

5. Ministry of health and family welfare. 2000. Bulletin on rural health statistics in India. New

6. National sample survey organization (NSSO). 1998. Morbidity and treatment of ailments

7. World bank. 1997b. India: new directions in health sector development at the state level: an operational perspective. Washington: world bank, report no. 15753-in.174 